\title{
Eletrofloculação seguido pela adição de moringa oleífera para $o$ tratamento de efluentes de lagoa de vinhaça
}

O setor sucroalcooleiro é responsável pela geração de uma grande quantidade do efluente líquido denominado de vinhaça, que possui alto poder polidor. Diante disso, o objetivo geral desse trabalho consiste em utilizar a técnica de eletrofloculação em conjunto com a utilização das sementes de Moringa oleífera no tratamento de efluentes proveniente de lagoas de vinhaça. Foram utilizados como parâmetros para avaliação da eficiência do processo os valores de turbidez, COT e DBO5. A etapa de eletrofloculação apresentou uma redução de $72 \%$ de COT, 36\% de DBO5 e $92 \%$ de turbidez. Na etapa onde foram adicionadas diferentes quantidades de pó das sementes de M. oleífera, a melhor condição de operação foi com a adição de 0,5 g.L-1 do pó das sementes de M. oleífera desengordurada com eficiência de redução de 70 \% DBO5 e $81 \%$ na turbidez. No entanto para o parâmetro COT nenhuma amostra apresentou resultados satisfatórios, devido ao incremento de matéria orgânica pela adição das sementes de M. oleífera no efluente. Ao avaliar a eficiência geral do processo (eletrofloculação aliada com a utilização das sementes) verificou-se para os parâmetros avaliados COT, DBO5 e turbidez uma redução significativa de $38 \%, 80 \%$ e $90 \%$ respectivamente. Concluise que a utilização da técnica de eletrofloculação aliada à utilização das sementes de M. oleífera desengordurada é uma alternativa limpa e com grande potencial para o tratamento de efluentes de vinhaça.

Palavras-chave: Eletrofloculação; Biopolímeros; Moringa oleífera; Vinhaça.

\section{Electrofloculation followed by the addition of moringa oleifera for the treatment of vinasse pond effluents}

\begin{abstract}
The sugar and alcohol sector is responsible for generating a large amount of liquid effluent called vinasse, which has a high polishing power. Therefore, the genera objective of this work is to use the electroflocculation technique in conjunction with the use of Moringa oleifera seeds in the treatment of effluents from vinasse ponds. As parameters to evaluate the efficiency of the process, the values of turbidity, TOC and DBO5 were used. The electrofloculation step showed a $72 \%$ reduction in TOC, $36 \%$ in BOD5 and $92 \%$ in turbidity. In the stage where different amounts of powder of $\mathrm{M}$. oleifera seeds were added, the best operating condition was with the addition of 0.5 gL-1 of the defatted M. oleifera seed powder, with a $70 \%$ reduction efficiency DBO5 and $81 \%$ in turbidity. However, for the COT parameter, no sample presented satisfactory results, due to the increase in organic matter by adding M. oleifera seeds in the effluent. When evaluating the overall efficiency of the process (electroflocculation combined with the use of seeds), a significant reduction of $38 \%, 80 \%$ and $90 \%$, respectively, was observed for the parameters evaluated COT, DBO5 and turbidity. It is concluded that the use of the electroflocculation technique combined with the use of defatted M. oleifera seeds is a clean alternative with great potential for the treatment of vinasse effluents.
\end{abstract}

Keywords: Electrofloculation; Biopolymers; Oil moringa; Stillage.

Topic: Desenvolvimento, Sustentabilidade e Meio Ambiente

Reviewed anonymously in the process of blind peer
Received: 05/10/2020

Approved: $\mathbf{2 6 / 1 1 / 2 0 2 0}$
Jean Paulo Silva Natal (iD

Universidade Cesumar, Brasil

http://lattes.cnpq.br/6465645151522534

http://orcid.org/0000-0001-6021-6442

jeanpsnatal@gmail.com

Adriano Valim Reis

Universidade Estadual de Maringá, Brasil

http://lattes.cnpq.br/8346176816805759

avreis77@gmail.com

Marcelo Teixeira Silva

Universidade Estadual de Maringá, Brasil http://lattes.cnpq.br/3090845425253198 http://orcid.org/0000-0002-6771-3254

teixeirasilvamarcelo82@gmail.com

\author{
Luiz Felipe Machado Velho (it) \\ Universidade Cesumar, Brasil \\ http://lattes.cnpq.br/3900847104121482 \\ http://orcid.org/0000-0001-8111-4955 \\ luiz.velho@unicesumar.edu.br
}

DOI: 10.6008/CBPC2179-6858.2020.006.0047

Referencing this:

NATAL, J. P. S.; REIS, A. V.; SILVA, M. T.; VELHO, L. F. M. Eletrofloculação seguido pela adição de moringa oleífera para o tratamento de efluentes de lagoa de vinhaça. Revista lbero Americana de Ciências Ambientais, v.11, n.6, p.583-599, 2020. DOI: http://doi.org/10.6008/CBPC2179-6858.2020.006.0047 


\section{INTRODUÇÃO}

Os impactos ambientais decorrentes do processo industrial de etanol e açúcar são significativos em virtude do grande consumo de água utilizada no processo e elevado volume de efluentes produzidos. Silva et al. (2006), classificam a vinhaça como o líquido residual do processo da produção de etanol e açúcar, rico em íons (principalmente sódio e potássio) os quais podem ser nocivos ao meio ambiente. Para cada litro de etanol produzido são gerados aproximadamente treze litros de vinhaça (EMBRAPA, 2015). Ramjeawon (2000), aponta o setor de alimentos como líder no consumo de água e geração de efluentes por unidade de produção.

A utilização da técnica de eletrofloculação no tratamento de efluentes industriais tem se mostrando eficaz e promissora, resultados positivos têm sido alcançados na clarificação de biodiesel, remoção de corantes da indústria têxtil, remoção de metais pesados entre outros. Cerqueira et al. (2009), descrevem que a técnica de eletrofloculação pode contribuir para o tratamento de efluentes líquidos uma vez que está remove materiais tóxicos e possibilita que o efluente tratado retorne ao meio ambiente dentro das especificações da legislação ambiental vigente.

Os biopolímeros são materiais biodegradáveis que tem apresentado resultados promissores na remoção de matéria orgânica natural de águas contaminadas. Além disso, consiste num material abundante e de fácil aplicação (CARVALHO, 2006). Dentre os biopolímeros disponíveis comercialmente destacam-se a pectina, quitina, quitosana, celulose, goma arábica e outros. São materiais obtidos a partir de certas frutas, legumes, madeira, casca de crustáceos, casulo de bicho da seda, dentre outros (HORN, 2008; HENNIG, 2009).

As sementes da M. oleífera apresentam em sua composição biopolímeros e têm sido empregadas no tratamento de água e efluentes. Os biopolímeros presentes nas sementes de $M$. oleífera possuem capacidade de coagular e flocular resíduos presentes em água, sendo assim muito utilizada no tratamento e clarificação de efluentes líquidos industriais (POZZOBON et al., 2015).

Este trabalho consiste em tratar efluentes líquidos de lagoas de vinhaça por meio da técnica de eletrofloculação seguida de adições de sementes de M. oleífera. Por ser um efluente gerado em quantidade significativa no Noroeste do Estado do Paraná a vinhaça foi o efluente escolhido para ser tratado e analisado neste estudo. As novas fontes de energias, tecnologias limpas e o consumo consciente, têm sido as principais ferramentas utilizadas na conciliação do desenvolvimento econômico e social aliadas com a preservação de recursos proveniente do meio ambiente (MELETI et al., 2012).

A vinhaça é um efluente líquido que é disposto diretamente, quase que diariamente, no solo e causa uma série de impactos negativos ao meio ambiente (EMBRAPA, 2015). Diante disso, o desenvolvimento de técnicas ou 'processo limpos' de tratamento de efluentes líquidos são atrativos e necessários dentro do atual cenário sócio-econômico-ambiental. A técnica de eletrofloculação aliada com a utilização de materiais ricos em biopolímeros (catiônicos e aniônicos) surge como uma técnica promissora e com alto potencial de aplicação se comparada aos processos convencionais de tratamentos de efluentes. Considerando o alto volume da vinhaça produzida atualmente pelo setor sucroalcooleiro e o impacto ambiental causado por este 
efluente torna-se justificável este estudo o qual propõe o emprego de técnicas limpas visando melhorar a qualidade do efluente.

\section{METODOLOGIA}

Para facilitar a compreensão da sequência dos processos estudados a Figura 5 apresenta as etapas do processo de eletrofloculação seguida pela aplicação da utilização dos biopolímeros obtidos através das sementes de M. oleifera.

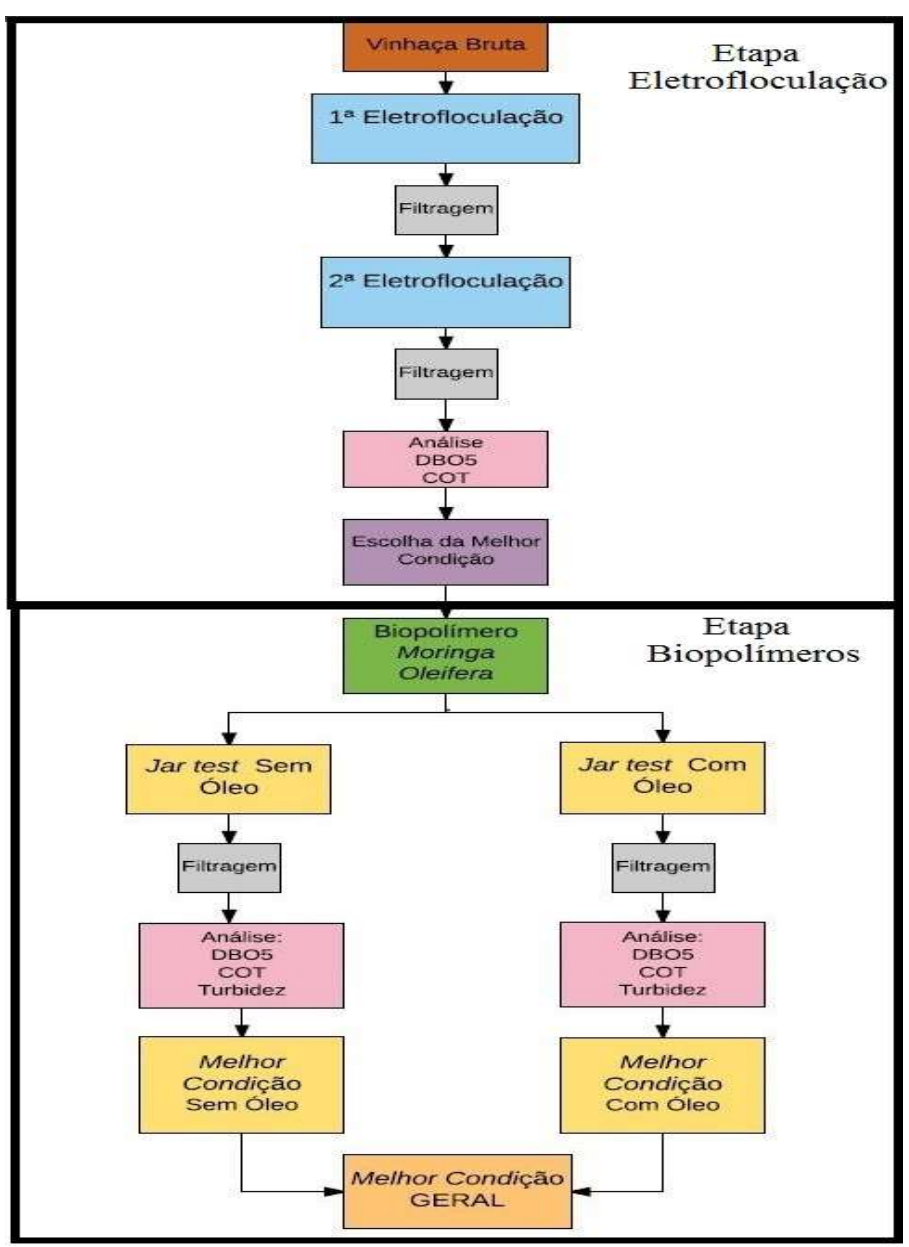

Figura 1: Organograma geral utilizado para o desenvolvimento do trabalho experimental.

O efluente estudado foi coletado no ponto de saída de uma lagoa de tratamento de vinhaça em uma unidade de produção sucroalcooleira, localizada na cidade de Maringá/PR. O efluente coletado foi conservado a uma temperatura de aproximadamente $10^{\circ} \mathrm{C}$ para não afetar as características físico-químicas e biológicas do mesmo.

A eletrofloculação foi realizada em ensaios de batelada no laboratório de Engenharia Ambiental e Sanitária da Unicesumar. Com o auxílio de uma fonte de energia modelo PHYWE Power Supply Universal com variação de voltagem ( 0 a $15 \mathrm{~V}$ ) e amperagem ( 0 a $6 \mathrm{~A})$. 0 reator utilizado foi um béquer de vidro com capacidade máxima de 1L, no qual foi inserido o sistema de eletrodos.

O conjunto de eletrodos foi construído com seis placas de alumínio cada uma medindo $10 \mathrm{~cm}$ de altura, $7 \mathrm{~cm}$ de largura e $0,3 \mathrm{~cm}$ de espessura, agrupadas paralelamente com uma distância de $0,5 \mathrm{~cm}$ entre 
si e presas por um parafuso passante medindo $8 \mathrm{~cm}$ de comprimento e $0,4 \mathrm{~cm}$ de diâmetro com arruelas de borracha medindo $0,5 \mathrm{~cm}$ de espessura com a função de isolar as placas. Conforme apresentado na Figura 2 .

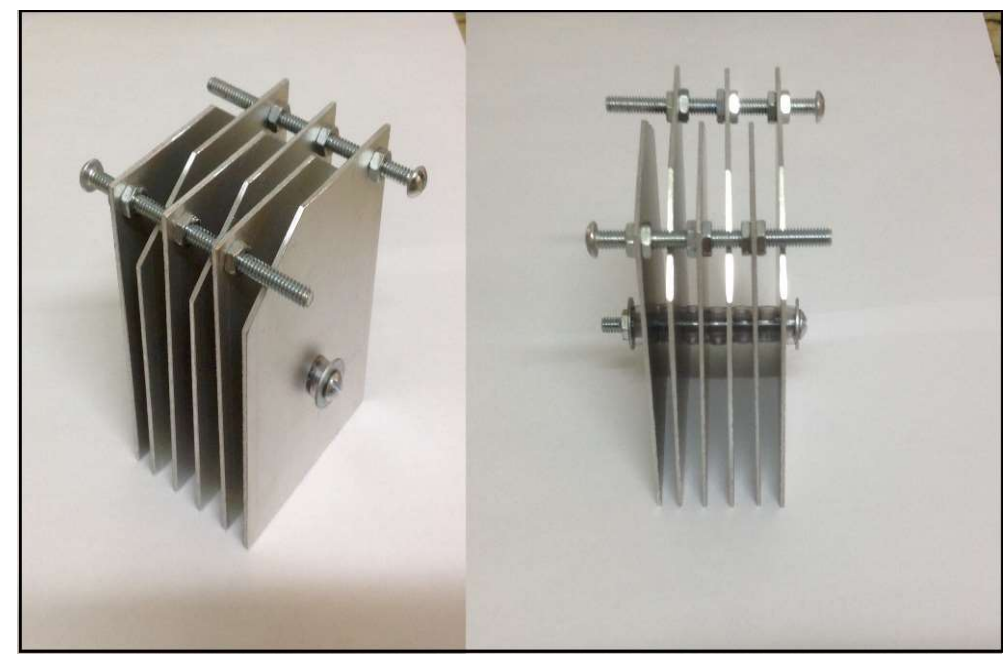

Figura 2: Eletrodo experimental em alumínio.

Com o intuito de otimizar o número de ensaios foi realizado um planejamento fatorial que tem a finalidade de obter as melhores condições operacionais do sistema (BRASIL et al., 2007). Button (2016), afirma que a metodologia de planejamento experimental se torna essencial no aprimoramento e desenvolvimento de processos, pois reduz o tempo de pesquisa, os custos envolvidos no processo e a variabilidade dos resultados.

Para o estudo foi determinado uma matriz de planejamento fatorial do tipo $3^{2}$ com os três níveis e dois fatores, sendo eles: intensidade de corrente elétrica (níveis 1, 3 e 5A) e o tempo de reação (30, 60 e 90 minutos). Desta forma foram utilizados 9 béqueres com $800 \mathrm{~mL}$ de vinhaça in natura cada. Na realização de cada ensaio foi mantida a temperatura ambiente e agitação constante com o auxílio de um agitador magnético. Após a realização de cada experimento as amostras foram filtradas em papel qualitativo e a polaridade do sistema invertida a fim de evitar o desgaste excessivo das placas e a formação de filmes de passivação que pudessem influenciar o desempenho do sistema.

Foram analisadas as concentrações de carbono orgânico total (COT) seguindo a metodologia e demanda bioquímica de oxigênio $\left(\mathrm{DBO}^{5}\right)$ através da metodologia (Standard Method $5210 \mathrm{~B}$ ) de cada amostra após o tratamento e comparadas com a vinhaça in natura. Com os dados obtidos construiu-se as superfícies de respostas para os parâmetros Amperagem e tempo de reação com o auxílio do programa Statistica ${ }^{R} 6.0$. Desta forma escolheu-se a melhor condição de operação do sistema de eletrofloculação para então iniciar a etapa de utilização dos biopolímeros da M. oleífera.

Para o preparo do coagulante natural foram utilizadas sementes de $M$. oleifera, obtidas em uma propriedade rural localizada no Município de Mandaguaçu - PR. Foi avaliada a eficiência de coagulação da $M$. oleifera com e sem óleo como tratamento secundário ao processo de eletrofloculação do efluente de vinhaça. As sementes foram descascadas e secas em estufa durante 6 horas à $65^{\circ} \mathrm{C}$. Concluída a secagem as sementes foram colocadas em um dissecador a vácuo por um período de duas horas. Finalizada essa etapa as sementes foram trituradas em um moinho de facas até formar um pó fino onde foi utilizado um conjunto 
de peneiras para obtenção de grânulos com diâmetro inferior a 0,5mm. Na Figura 3, tem-se da esquerda para direita as sementes de $M$. oleífera com cascas, descascadas e moídas.

Finalizada essa etapa as sementes foram trituradas em um moinho de facas até formar um pó fino onde foi utilizado um conjunto de peneiras para obtenção de grânulos com diâmetro inferior a 0,5mm. $\mathrm{Na}$ Figura 3, tem-se da esquerda para direita as sementes de $M$. oleífera com cascas, descascadas e moídas.

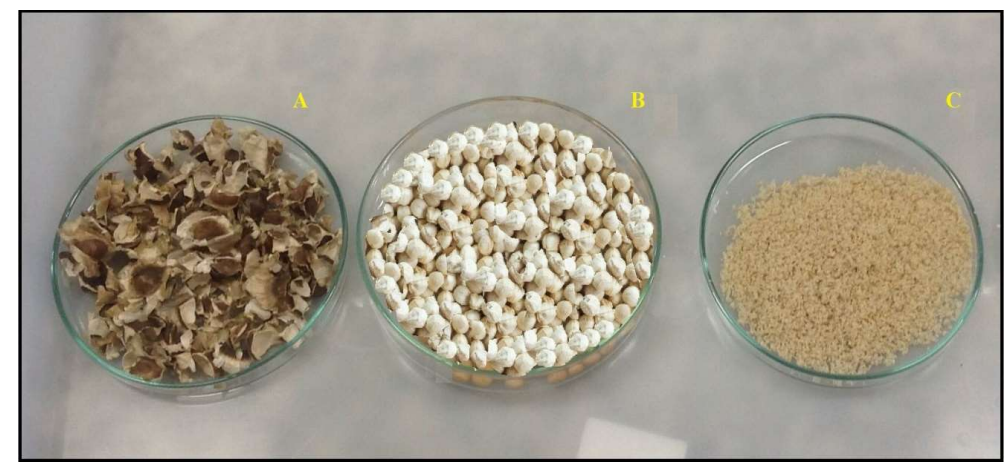

Figura 3: Sementes de Moringa oleifera (A) com cascas, (B) descascadas e (C) moídas.

Para o estudo foi estabelecido a análise dos efeitos coagulantes do pó das sementes de $M$. oleífera in natura sob as concentrações $\left(0,5 \mathrm{~g} \cdot \mathrm{L}^{-1}, 1 \mathrm{~g} \cdot \mathrm{L}^{-1}, 2 \mathrm{~g} \cdot \mathrm{L}^{-1}, 4 \mathrm{~g} \cdot \mathrm{L}^{-1}, 8 \mathrm{~g} \cdot \mathrm{L}^{-1}\right)$. E, também, os efeitos coagulantes do pó das sementes após a extração do óleo presente nas mesmas, respeitando as mesmas concentrações (0,5

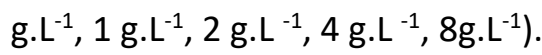

Para a extração do óleo das sementes de M. oleífera foi utilizada a técnica de extração por Soxhlet que é comumente empregada na determinação de óleos, graxas e gorduras. Após o processo de extração do óleo as sementes foram secas em uma estufa (De Leo 665) durante um período de 6 horas à $65^{\circ} \mathrm{C}$. No final desta etapa obteve-se o pó da Moringa sem o óleo.

Após o preparo do pó da Moringa e a separação das amostras (com e sem óleo), ocorreram os ensaios de coagulação, utilizando o equipamento Jar Test modelo (QUIMIS Q305F). Para os ensaios utilizouse 10 béquers contendo cada um $900 \mathrm{~mL}$ de efluente no qual foram adicionadas as quantidades preestabelecidas do coagulante $M$. oleifera. A velocidade utilizada no Jar Test tanto para mistura rápida quanto para mistura lenta foram fixadas em respectivamente: $95 \mathrm{rpm}$ e $35 \mathrm{rpm}$.

Em relação aos valores do tempo de mistura rápida, mistura lenta e de sedimentação foram baseados no estudo desenvolvido por Ströher et al. (2012), onde padronizaram os tempos de mistura rápida, mistura lenta e sedimentação em 3, 30 e 20 minutos.

Ao final de cada ensaio as amostras foram filtradas em papel qualitativo a fim de retirar o material coagulado e em seguida encaminhadas para realização das análises de $\mathrm{COT}, \mathrm{DBO} 5$ e turbidez a fim de avaliar a eficiência do tratamento com a utilização de M. oleífera.

\section{RESULTADOS E DISCUSSÃO}

\section{Redução COT no processo de Eletrofloculação}

Foram avaliados os fatores intensidade de corrente elétrica (níveis 1,3 e $5 \mathrm{~A}$ ) e o tempo de 
eletrofloculação (30, 60 e $90 \mathrm{~min}$ ) na redução do COT e da $\mathrm{DBO}_{5}$. Na Tabela 1 tem-se a matriz planejamento do planejamento fatorial $3^{2}$ e os resultados obtidos relativos à redução do COT obtido da vinhaça in natura.

Tabela 1: Matriz do planejamento fatorial 32 e os percentuais de redução do COT obtidos da vinhaça in natura.

\begin{tabular}{|l|l|l|l|}
\hline \multirow{2}{*}{ Análises } & Fatores & Amperes (A) & Respostas \\
\cline { 2 - 4 } & Tempo (min) & 1 & Red COT \% \\
\hline $\mathbf{0 1}$ & 30 & 3 & 58,82 \\
\hline $\mathbf{0 2}$ & 30 & 5 & 61,76 \\
\hline $\mathbf{0 3}$ & 30 & 1 & 65,69 \\
\hline $\mathbf{0 4}$ & 60 & 3 & 62,75 \\
\hline $\mathbf{0 5}$ & 60 & 5 & 64,71 \\
\hline $\mathbf{0 6}$ & 60 & 1 & 59,80 \\
\hline $\mathbf{0 7}$ & 90 & 3 & 71,57 \\
\hline $\mathbf{0 8}$ & 90 & 5 & 70,60 \\
\hline $\mathbf{0 9}$ & 90 & & 69,61 \\
\hline
\end{tabular}

Foram realizadas análises estatísticas para avaliar as influências variáveis independentes tempo de eletrofloculação (Min) e intensidade de corrente elétrica (A) na redução do COT\%. Admitiu-se um nível de significância de $5 \%$, sendo significativos os fatores e suas interações cuja o p-valor $<0,05$. Na Tabela 2 temse os dados da análise de variância (ANOVA). Ficou evidente, com base no $p$-valor, que o tempo de eletrofloculação é o parâmetro mais significativo para a redução do COT\% da vinhaça. Já a amperagem aplicada foi significância somente quando associada ao tempo de eletrofloculação.

Tabela 2: Resultados da ANOVA referentes às análises de Redução COT\%. Os termos t e A referem-se aos fatores tempo de eletrofloculação e amperagem no eletrotodo imerso na vinhaça in natura.

\begin{tabular}{|l|l|l|l|l|l|}
\hline Parâmetros & SQ & GL & MQ & Valor de $\boldsymbol{F}$ \\
\hline $\mathbf{T}$ & 108,3445 & 1 & 108,3445 & 122,8396 & Valor de $\boldsymbol{P}$ \\
\hline $\mathbf{t}^{\mathbf{2}}$ & 30,7295 & 1 & 30,7295 & 0,0015 & 34,8407 \\
\hline $\mathbf{t} \mathbf{~ A}$ & 19,4970 & 1 & 19,4970 & 22,1055 & 0,0097 \\
\hline $\mathbf{t}^{\mathbf{2}} \mathbf{~ A}$ & 9,7068 & 1 & 9,7068 & 11,0054 & 0,0182 \\
\hline $\mathbf{t}^{\mathbf{2}} \mathbf{x} \mathbf{A}^{\mathbf{2}}$ & 6,0154 & 1 & 6,0154 & 0,0451 & 0,0795 \\
\hline Erro puro & 2,6460 & 3 & 0,8820 & & \\
\hline Totais & 176,9394 & 8 & & & \\
\hline
\end{tabular}

O ajuste da superfície aos dados experimentais foi enfatizado pelos valores dos coeficientes de determinação $R^{2}$ e determinação ajustada $R^{2}$ adj cujos valores foram de 0,9850 e 0,9601 respectivamente. $\mathrm{Na}$ Figura 4 observou-se uma redução significativa no COT\% da vinhaça nos maiores tempos de eletrofloculação. Reduções do COT próximos à 70\% foram alcançadas nas eletrofloculações de 90min. 


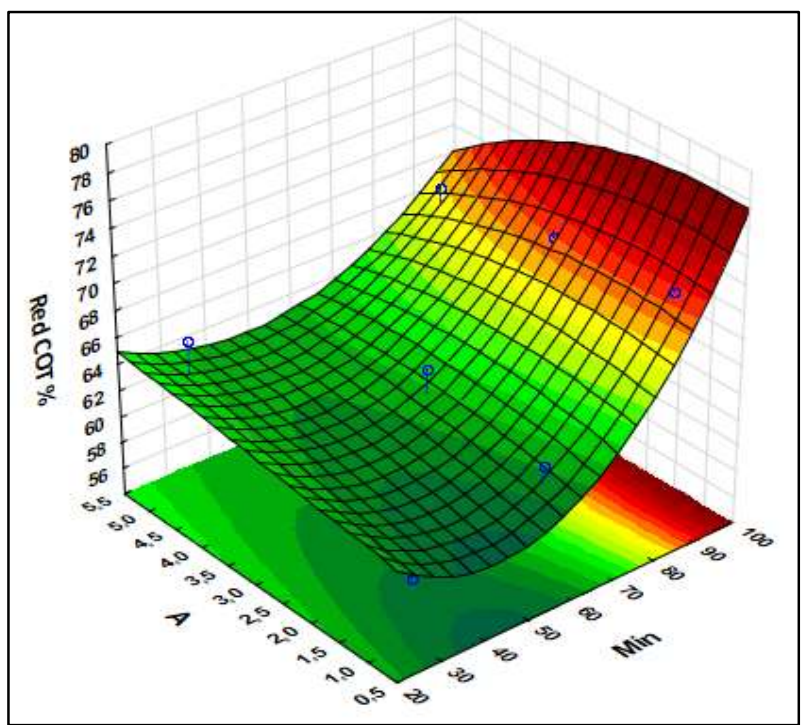

Figura 4: Superfície de resposta referente à variação da Red COT \% em função da intensidade de corrente elétrica (A) e do tempo de eletrofloculação (min).

A Equação 01 refere-se o modelo matemático gerado a partir do planejamento fatorial $3^{2}$ sendo este capaz de estimar (com $\mathrm{R}^{2}$ adj $=96,01 \%$ ) a redução do COT\% para a vinhaça.

$$
\text { Red COT\% }=69,6-0,4901 t+0,0056 t^{2}+0,0363 t A-0,00029 t^{2} A-0,000037 t^{2} A^{2}
$$

Pode-se observar a partir da Tabela 2 e Figura 4 que no Ensaio 07 (1A e $90 \mathrm{~min}$ ) houve uma maior eficiência na redução de COT atingindo 71,57\%. Na Tabela 3 tem-se comparativos da redução COT\% da vinhaça deste estudo e de estudos desenvolvidos pelos autores Davila et al. (2011), Yavuz (2007) e Cardona et al. (2013).

Tabela 3:Comparativo sobre a redução do COT\% da vinhaça através da técnica de eletrofloculação desenvolvidas por diferentes pesquisadores.

\begin{tabular}{|l|l|l|l|}
\hline Autores & Tratamento & Distância entre eletrodos (mm) & Redução COT (\%) \\
\hline $\begin{array}{l}\text { Presente Trabalho } \\
\text { (1 A. e 90 Minutos) }\end{array}$ & Vinhaça & $5 \mathrm{~mm}$ & $71,9 \%$ \\
\hline Davila et al. (2011) & Vinhaça & $10 \mathrm{~mm}$ & $25 \%$ \\
\hline Yavuz (2007) & Vinhaça & $3 \mathrm{~mm}$ & $88,7 \%$ \\
\hline Cardona et al. (2013) & Vinhaça & $3 \mathrm{~mm}$ & $88 \%$ \\
\hline
\end{tabular}

Na Tabela 3 os resultados de Yavuz (2007) e Cardona et al. (2013) foram próximos dos apresentados neste trabalho. Porém, o resultado de Davila et al. (2011) encontrou-se distante dos demais e está discrepância de valor teve relação com a distância dos eletrodos empregado durante a eletrofloculação. De acordo com Crespilho et al. (2004) em seus estudos, a distância entre os eletrodos influência no desempenho do sistema, quanto maior a distância entre os eletrodos maior a carga necessária para eficiência do processo.

\section{Redução $\mathrm{DBO}_{5}$ no processo de Eletrofloculação}

$\mathrm{Na}$ Tabela 4 têm-se os dados referentes à redução da $\mathrm{DBO}_{5}$, através dos ensaios realizados a partir do planejamento fatorial $3^{2}$.

Tabela 4:Matriz do planejamento fatorial $3^{2}$ e os percentuais de redução $\mathrm{DBO}_{5}$ obtidos a paritr da vinhaça in natura.

\begin{tabular}{|l|l|l|l|}
\hline \multirow{2}{*}{ Análises } & Fatores & Respostas \\
\cline { 2 - 4 } & Tempo ( $\mathbf{m i n})$ & 1 & Red DBO \\
\hline $\mathbf{0 1}$ & 30 & 1 & 30,30 \\
\hline
\end{tabular}




\begin{tabular}{|l|l|l|l|}
\hline 02 & 30 & 3 & 27,38 \\
\hline 03 & 30 & 5 & 30,92 \\
\hline 04 & 60 & 1 & 30,93 \\
\hline 05 & 60 & 3 & 24,48 \\
\hline 06 & 60 & 5 & 28,20 \\
\hline 07 & 90 & 1 & 35,40 \\
\hline 08 & 90 & 3 & 27,76 \\
\hline 09 & 90 & 5 & 36,69 \\
\hline
\end{tabular}

Foram realizadas as análises estatísticas relativas aos valores da redução da $\mathrm{DBO}_{5}$ com um nível de significância de 5\%, sendo significativos os fatores e as interações cujo p-valor $<0,05$. Os dados da análise de variância (ANOVA) foram expressos na Tabela 5.

Tabela 5: Resultados da ANOVA relativos às análises de Red DBO5\%. Os termos t e A referem-se aos fatores tempo de eletrofloculação e amperagem no eletrotodo imerso na vinhaça in natura

\begin{tabular}{|l|l|l|l|l|l|}
\hline Parâmetros & SQ & GL & MQ & Valor de $\boldsymbol{F}$ & Valor de $\boldsymbol{P}$ \\
\hline $\mathbf{T}$ & 21,0678 & 1 & 21,0678 & 147,9864 & 0,0012 \\
\hline $\mathbf{t}^{\mathbf{2}}$ & 24,9970 & 1 & 24,9970 & 175,5858 & 0,0009 \\
\hline $\mathbf{A}^{\mathbf{2}}$ & 61,1621 & 1 & 61,1621 & 429,6196 & 0,0002 \\
\hline $\mathbf{t} \mathbf{x} \mathbf{A}^{\mathbf{2}}$ & 8,5241 & 1 & 8,5241 & 59,8760 & 0,0044 \\
\hline $\mathbf{t}^{\mathbf{2}} \mathbf{A}$ & 4,5427 & 1 & 4,5427 & 31,9095 & 0,0109 \\
\hline Erro puro & 0,4270 & 3 & 0,1423 & & \\
\hline Totais & 120,7210 & 8 & & & \\
\hline
\end{tabular}

O ajuste da superfície aos dados experimentais foi enfatizado por meio dos valores dos coeficientes de determinação $R^{2}$ e determinação ajustada $R^{2}{ }_{\text {adj }}$ cujos valores foram de 0,9964 e 0,9905 respectivamente. Verificou-se por base $p$-valor que os parâmetros $\mathbf{t}, \mathbf{t}^{2}$ e $\mathbf{A}^{2}$ foram os termos mais significativos para a redução da $\mathrm{DBO}_{5}$. Na Figura 5 as maiores reduções da $\mathrm{DBO}_{5}$ ocorreram com eletrofloculação de 90 min e nas amperagens de $1 \mathrm{~A}$ e $5 \mathrm{~A}$. Neste caso, os ensaios 07 e 09 apresentaram os melhores resultados com $35,3 \%$ e $36,6 \%$ de remoção de $\mathrm{DBO}_{5}$ respectivamente.

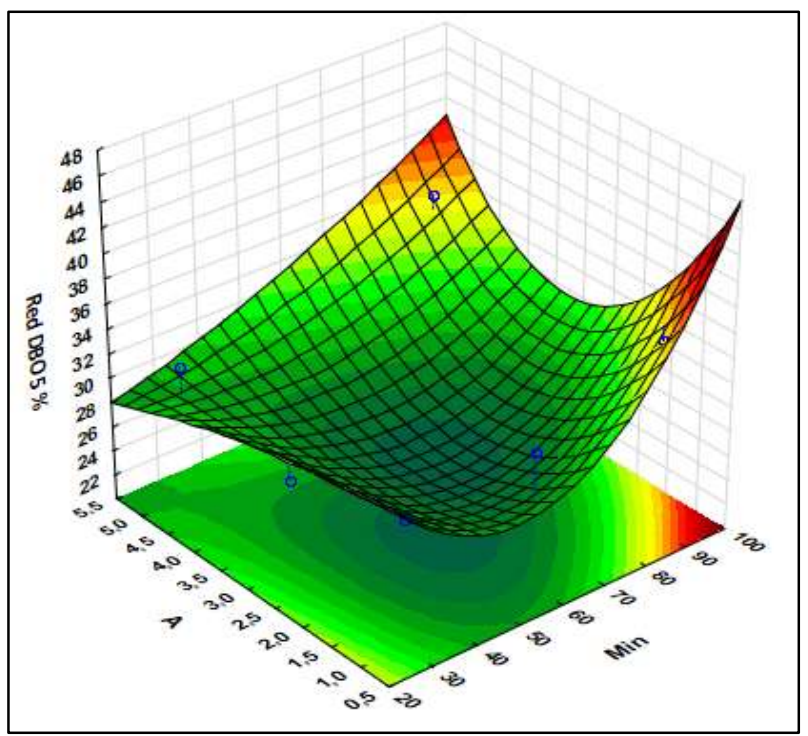

Figura 5: Superfície de resposta referente à variação da Red $\mathrm{DBO}_{5}$ em função da intensidade de corrente elétrica (A) e do tempo de eletrofloculação (Min).

Considerou-se o Ensaio 07 o mais eficiente visto que este envolve um menor consumo energético uma vez que operou com uma amperagem menor do que o Ensaio 09. A Equação 02 refere-se o modelo matemático gerado a partir do planejamento fatorial $3^{2}$ sendo este capaz de estimar (com $R^{2}{ }_{\text {adj }}=99,05 \%$ ) a 
redução do $\mathrm{DBO}_{5} \%$ para a vinhaça.

Red DBO5\% $=45,64-0,7021 t+0,0076 t^{2}-0,632 A^{2}+0,02519 t A^{2}-0,001240 t^{2} A$

$\mathrm{Na}$ Tabela 6 tem-se os resultados dos percentuais de redução da $\mathrm{DBO}_{5}$ deste estudo e os relatados por Paz-Pino et al. (2014) e Guerreiro et al. (2016) para o tratamento de vinhaça via eletrofloculação.

Tabela 6:Comparativo relativo à redução da DBO5 da vinhaça pela técnica de eletrofloculação.

\begin{tabular}{|l|l|l|}
\hline Autores & Tratamento & Redução DBO (\%) $^{\text {(\%) }}$ \\
\hline Presente Trabalho (1 A. e 90 Minutos) & Vinhaça & 35 \\
\hline Paz-Pino et al. (2014) & Vinhaça & 16 \\
\hline Guerreiro et al. (2016) & Vinhaça & 27,9 \\
\hline
\end{tabular}

Os valores de redução de $\mathrm{DBO}_{5} \%$ não foram muito expressivos, contudo como afirmam Paz-Pino et al. (2014) e Guerreiro et al. (2016), o tratamento por eletrofloculação quando combinado com outras formas de tratamento tendem a aumentar significativamente a eficiência de remoção. Paz-Pino et al. (2014) descrevem que o efluente de vinhaça após a etapa de eletrofloculação, se submetido a um processo de digestão anaeróbica a aumentar significativamente a redução de $\mathrm{DBO}_{5}$. Verificaram que a redução de $16 \%$ (tratamento de eletrofloculação) passou para 83 \% com a digestão anaeróbica.

Guerreiro et al. (2016) também apontam que o tratamento de eletrofloculação por si só não alcança grandes resultados na redução da $\mathrm{DBO}_{5}$, contudo, quando a eletrofloculação foi combinada com a técnica de oxidação Fenton ocorreu uma elevação na redução da $\mathrm{DBO}_{5}$ de $16 \%$ para 45,7\%.

\section{Redução da turbidez no processo de eletrofloculação}

Após a escolha da melhor condição de operação do sistema de eletrofloculação (1 A. e 90 Min.), foi analisado a eficiência da redução de turbidez. A Tabela 7 demonstra esses valores, juntamente com os resultados relatados pelos autores Paz-Pino et al. (2014), Davila et al. (2016) e Zayas et al. (2007).

Tabela 7: Comparativo sobre a redução da turbidez da vinhaça através da técnica de eletrofloculação.

\begin{tabular}{|l|l|l|}
\hline Autores & Tratamento & Redução Turbidez (\%) \\
\hline Presente Trabalho (1 A. e 90 Minutos) & Vinhaça & 92,6 \\
\hline Paz-Pino et al (2014) & Vinhaça & 99 \\
\hline Davila et al. (2016) & Vinhaça & 89 \\
\hline Zayas et al. (2007) & Vinhaça & 100 \\
\hline
\end{tabular}

Verifica-se na Tabela 7 que os valores de redução de turbidez encontram-se todos acima de $89 \%$ de redução, isso indica que o processo de eletrofloculação da vinhaça é extremamente eficiente em relação ao parâmetro turbidez. A Figura 6 apresenta um comparativo visual entre a vinhaça in natura e a submetida a melhor condição de operação do sistema de eletrofloculação (90 min. e 1 A). Onde apresentou uma redução de turbidez de $92,6 \%$. 


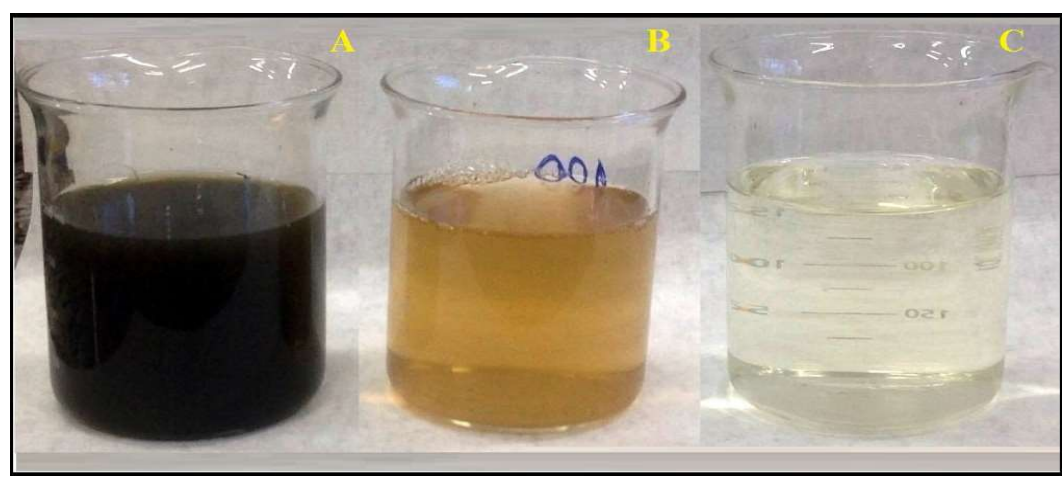

Figura 6: Comparativo: (A) vinhaça in natura, (B) primeira etapa eletrofloculação e (C) Segunda etapa eletrofloculação.

A Tabela 8 indica o percentual de redução de DBO5, COT e turbidez através da técnica de eletrofloculação. Comparando a vinhaça in natura e a melhor condição de operação (90 min. e 1 A) determinadas com base nas superfícies de respostas.

Tabela 8: Eficiência de redução de $\mathrm{DBO}_{5}$, $\mathrm{COT}$ e tutbidez entre a vinhaça in natura e a melhor condição determinada no processo (90 min. e 1 A).

\begin{tabular}{|l|l|l|l|}
\hline Parâmetro Avaliado & Vinhaça in natura & Melhor Condição (90 min. e 1 A) & Redução \% \\
\hline DBO ${ }_{5}\left(\mathrm{mg}^{-\mathrm{L}^{-1}}\right)$ & $6.428 \mathrm{mg} \cdot \mathrm{L}^{-1}$ & $4.187 \mathrm{mg} \cdot \mathrm{L}^{-1}$ & $35 \%$ \\
\hline COT $\left(\mathrm{mg} \cdot \mathrm{L}^{-1}\right)$ & $248,78 \mathrm{mg} \cdot \mathrm{L}^{-1}$ & $70,73 \mathrm{mg} \cdot \mathrm{L}^{-1}$ & $72 \%$ \\
\hline Turbidez (NTU) & $35,6 \mathrm{NTU}$ & $2,63 \mathrm{NTU}$ & $92,6 \%$ \\
\hline
\end{tabular}

Como se pode observar na Tabela 8, na etapa de eletrofloculação com a escolha da melhor condição de operação do sistema (90 min. e $1 \mathrm{~A}$ ) a redução de $\mathrm{DBO}_{5}$, COT e turbidez alcançaram respectivamente $35 \%$, $72 \%$ e $92,6 \%$.

\section{Análise do COT com a adição de M. oleífera}

Após a determinação da melhor condição de operação do sistema de eletrofloculação (90 min e 1 A) foram realizadas as análises referentes à redução do carbono orgânico total com a adição de diferentes concentrações M. oleífera com e sem óleo. A tabela 9 apresenta um comparativo da concentração do COT com a adição do pó das sementes de M. oleífera com e sem óleo.

Tabela 9: Percentual de acréscimo do COT turbidez com o incremento de diferentes concentrações de M. oleifera com e sem óleo.

\begin{tabular}{|l|l|l|l|}
\hline Amostras & Concentração de sementes M. oleifera (g. $\mathbf{L}^{-1}$ ) & Concentração COT (mg.L $\mathbf{L}^{-1}$ ) & Acréscimo COT (\%) \\
\hline Efluente (90 min 1 A). & & 70,73 & ------ \\
\hline Amostra. 01 (A) & 0,5 & 112,2 & $+58,5 \%$ \\
\hline Amostra. 02 (A) & 1 & 129,3 & $+84 \%$ \\
\hline Amostra. 03 (A) & 2 & 187,8 & $+165,5 \%$ \\
\hline Amostra. 04 (A) & 4 & 229,3 & $+224 \%$ \\
\hline Amostra. 05 (A) & 8 & 278,1 & $+293 \%$ \\
\hline Amostra. 06 (B) & 0,5 & 153,66 & $+112 \%$ \\
\hline Amostra. 07 (B) & 1 & 170,73 & $+140 \%$ \\
\hline Amostra. 08 (B) & 2 & 229,30 & $+224 \%$ \\
\hline Amostra. 09 (B) & 4 & 287,80 & $+305 \%$ \\
\hline Amostra. 10 (B) & 8 & 580,48 & $+720 \%$ \\
\hline
\end{tabular}

(A) Sementes de M. oleífera com óleo (B) Sementes de M. oleiffera sem óleo

A Figura 7 exemplifica melhor a concentração do carbono orgânico total com a adição de diferentes concentrações de $M$. oleífera. 


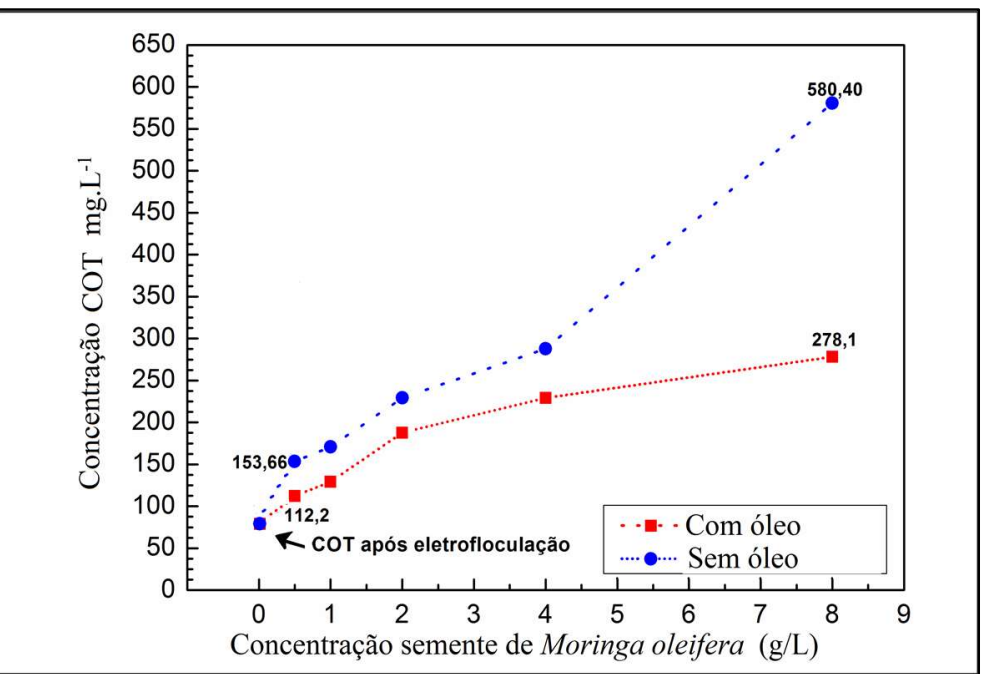

Figura 7:Comparativo da concentração do COT com o pó da Moringa com e sem óleo

Ao analisar a Tabela 8 nota-se que a quantidade de COT sofre uma redução com o processo de eletrofloculação, partindo de $248,78 \mathrm{mg} \cdot \mathrm{L}^{-1} \mathrm{com}$ a vinhaça in natura e atingindo $70,73 \mathrm{mg} \cdot \mathrm{L}^{-1} \mathrm{com}$ o processo de eletrofloculação. No entanto percebe-se na Figura 7 que a quantidade de COT aumenta com a adição do pó de M. oleífera, este aumento acompanha o incremento das diferentes concentrações do pó das sementes, este aumento na concentração de COT está intimamente ligado ao fato de que a M. oleifera é um coagulante natural e possui em sua composição elevadas concentrações de lipídios, proteínas, açucares dentre outros elementos orgânicos que proporcionam uma maior concentração do carbono orgânico total (GALLÃO et al., 2006).

Desta forma, possivelmente se ocorresse uma nova etapa de eletrofloculação do efluente após a etapa de coagulação com Moringa o carbono orgânico total presente no efluente poderia ser retirado. Como o ocorrido na etapa de eletrofloculação onde os percentuais de remoção do COT atingiram 70\% de eficiência.

\section{Análise da turbidez com a adição de $M$. oleífera}

$\mathrm{Na}$ Tabela 10 tem-se os valores referentes a redução da turbidez avaliando a vinhaça in natura, após passar pela etapa de eletrofloculação e depois de receber as diferentes concentrações do pó da semente de M. oleifera.

Tabela 10:Percentual de remoção e acréscimo da turbidez com o incremento de diferentes concentrações de $M$. oleifera com e sem óleo.

\begin{tabular}{|c|c|c|c|}
\hline Amostras & $\begin{array}{l}\text { Concentração de sementes } M \text {. oleífera (g.L' } \\
{ }^{1} \text { ) }\end{array}$ & Concentração Turbidez (NTU) & $\begin{array}{l}\text { Acréscimo ou redução de Turbidez } \\
\text { (\%) }\end{array}$ \\
\hline Efluente (90 min $1 \mathrm{~A})$. & ( & 2,63 & ----- \\
\hline Amostra. $01^{\text {(A) }}$ & 0,5 & 0,72 & $-72,5$ \\
\hline Amostra. $02^{\text {(A) }}$ & 1 & 1,89 & -28 \\
\hline Amostra. $03^{(\mathrm{A})}$ & 2 & 8,58 & +226 \\
\hline Amostra. $04^{\text {(A) }}$ & 4 & 9,43 & +299 \\
\hline Amostra. $05^{\text {(A) }}$ & 8 & 27,4 & +1061 \\
\hline Amostra. $06^{\text {(B) }}$ & 0,5 & 0,48 & -81 \\
\hline Amostra. $07^{\text {(B) }}$ & 1 & 3,97 & +50 \\
\hline Amostra. $08^{\text {(B) }}$ & 2 & 12,8 & +381 \\
\hline Amostra. $09^{\text {(B) }}$ & 4 & 38,9 & +1380 \\
\hline Amostra. $10^{\text {(B) }}$ & 8 & 42,2 & +1500 \\
\hline
\end{tabular}

(A) Sementes de M. oleífera com óleo (B) Sementes de M. oleifera sem óleo 
A Figura 8 apresenta um comparativo visual sobre a influência da adição de diferentes concentrações de $M$. oleífera sobre o efluente, comparado com os valores iniciais e após a etapa de eletrofloculação.

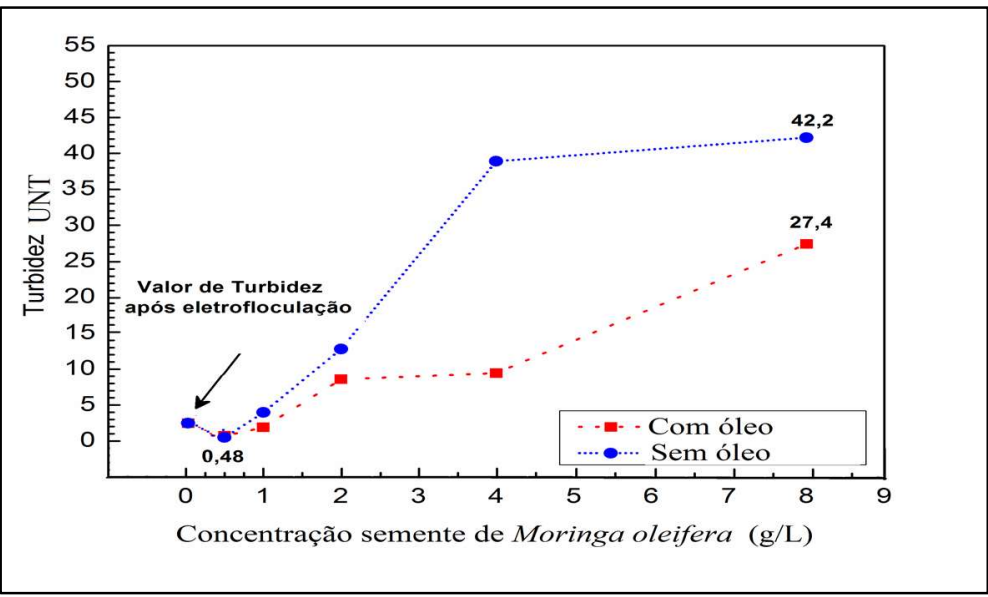

Figura 8: Comparativo da concentração de turbidez com o pó da semente de Moringa com e sem óleo.

Analisando a Tabela 10 e a Figura 8 vê-se que os valores referentes à turbidez sofrem uma ligeira queda com a adição de 0,5 g. $\mathrm{L}^{-1}$ do pó das sementes com e sem óleo. Contudo com a adição das demais concentrações do pó das sementes de $M$. oleífera a concentração de turbidez se eleva gradativamente.

Desta forma, tem-se uma noção de que apenas as amostras 01, 02 e 06 tiveram efeito na redução da turbidez, sendo que somente as amostras 01 e 06 reduziram a turbidez de maneira significativa com respectivamente 72,5 \% e 81 \% de redução. O aumento na turbidez está ligado ao fato de ter sido adicionado uma grande quantidade de material orgânico (Pó da semente de Moringa) no tratamento da vinhaça. Von Sperling (2014) afirma que a presença de material sólido em suspensão em efluentes leva ao aumento da turbidez diminuindo a passagem da luz.

Os resultados obtidos na redução de turbidez de efluentes de vinhaça com a utilização de $M$. oleífera são semelhantes aos desenvolvidos por Ströher et al. (2012) onde os autores estudaram os efeitos da aplicação de $M$. oleífera na redução de turbidez de efluentes de lavagem de jeans, os autores conseguiram uma eficiência de remoção de 91,1\%. Santos et al. (2010) conseguiram atingir uma eficiência de remoção de 97 \% com a aplicação de sementes de Moringa em efluentes de curtume.

Santiago et al. (2009) em seus estudos avaliaram diferentes coagulantes naturais, dentre eles a $M$. oleiffera. Os autores obtiveram uma eficiência de $90 \%$ na remoção da turbidez presente no efluente de vinhaça.

Desta forma a aplicação do pó da semente de M. oleífera no tratamento de vinhaça mostrou-se uma alternativa eficiente na remoção de turbidez. Nota-se também que a amostra 01 com concentração de 0,5 g. $\mathrm{L}^{-1}$ de Moringa com óleo e a amostra 06 com concentração de 0,5 g. $\mathrm{L}^{-1}$ de Moringa sem óleo apresentaram índices elevados na redução de turbidez $72 \%$ e 81 \%, respectivamente.

Sendo assim, a utilização do pó das sementes de Moringa após o processo de extração do óleo é uma alternativa viável no tratamento de efluentes de vinhaça. 


\section{Análise da $\mathrm{DBO}_{5}$ com a adição de $M$. oleífera}

Como era esperado o pó das sementes de $M$. oleífera influenciou positivamente na redução da $\mathrm{DBO}_{5}$ na maioria das amostras, tanto nas concentrações com óleo quanto nas concentrações de Moringa sem óleo. A Tabela 11 retrata a quantidade de $\mathrm{DBO}_{5}$ presente na vinhaça in natura, na vinhaça submetida a melhor condição de eletrofloculação (90 min e 1 A) e na vinhaça após receber as diferentes concentrações de $M$. oleífera com e sem óleo.

Tabela 11: Porcentagem de redução da $\mathrm{DBO}_{5}$ com o incremento de diferentes concentrações de Moringa oleifera com e sem óleo.

\begin{tabular}{|c|c|c|c|}
\hline Amostras & Concentração de sementes $M$. oleífera $\left(\mathrm{g} \cdot \mathrm{L}^{-1}\right)$ & $\begin{array}{l}\text { Concentração } \\
\mathrm{DBO}_{5}\left(\mathrm{mg}^{\mathrm{L}} \mathrm{L}^{-1}\right)\end{array}$ & Acréscimo ou redução da $\mathrm{DBO}_{5}(\%)$ \\
\hline Efluente $(90 \mathrm{~min} 1 \mathrm{~A})$. & & 4187 & $\begin{array}{ll}----- \\
\end{array}$ \\
\hline Amostra. $01^{\text {(A) }}$ & $\overline{0,5}$ & 4293 & $+2,5$ \\
\hline Amostra. $02^{\text {(A) }}$ & 1 & 1197 & $-71,5$ \\
\hline Amostra. 03 (A) & 2 & 2432 & -42 \\
\hline Amostra. 04 (A) & 4 & 2457 & $-41,5$ \\
\hline Amostra. 05 (A) & 8 & 4145 & -1 \\
\hline Amostra. 06 (B) & 0,5 & 1245 & -70 \\
\hline Amostra. 07 (B) & 1 & 1394 & $-66,7$ \\
\hline Amostra. $08^{\text {(B) }}$ & 2 & 2458 & -41 \\
\hline Amostra. $09^{\text {(B) }}$ & 4 & 4046 & $-3,4$ \\
\hline Amostra. $10^{\text {(B) }}$ & 8 & 3845 & -8 \\
\hline
\end{tabular}

(A) Sementes de M. oleífera com óleo (B) Sementes de M. oleífera sem óleo

A Figura 9 demonstra de maneira mais clara a redução da $\mathrm{DBO}_{5}$ partindo da vinhaça in natura, sendo submetida a melhor condição de eletrofloculação e, posteriormente, com a utilização do pó de M. oleífera com e sem óleo.

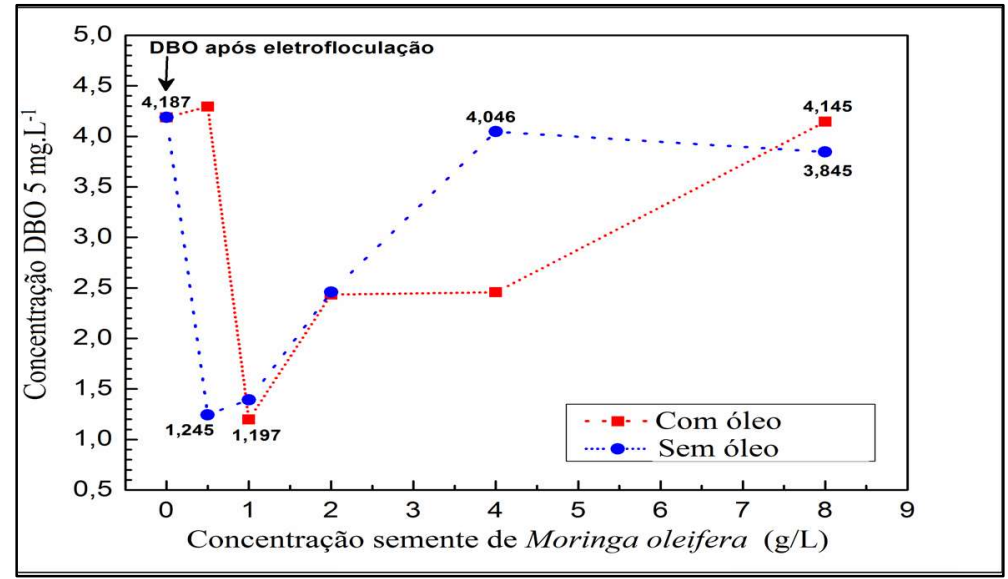

Figura 9: Comparativo da concentração de $\mathrm{DBO}_{5}$ com a adição do pó da semente de Moringa com e sem óleo.

Analisando a Tabela 11 e a Figura 9 nota-se que a concentração de $\mathrm{DBO}_{5}$ presente no efluente de vinhaça in natura reduz de $6428 \mathrm{mg} \cdot \mathrm{L}^{-1}$ para $4187 \mathrm{mg} \cdot \mathrm{L}^{-1}$ através do emprego da técnica de eletrofloculação. No entanto, foi com a utilização do pó das sementes de $M$. oleifera que a redução se demonstrou eficiente.

Percebe-se que a utilização de sementes de $M$. oleiffera na redução da $\mathrm{DBO}_{5}$ obtivera resultados significativos, exceto para a amostra 01 que apresentou uma $\mathrm{DBO}_{5}$ de $4293 \mathrm{mg} \cdot \mathrm{L}^{-1}$ após a adição de 0,5 g.L ${ }^{-1}$ de Moringa com óleo, valor esse superior ao inicial. Contudo as demais amostras reduziram a concentração de $\mathrm{DBO}_{5}$ com a adição do pó das sementes de $M$. Oleífera. 
Verifica-se na Tabela 11 que a amostra 01 foi a única que aumentou a concentração de $\mathrm{DBO}_{5}$ atingindo $4293 \mathrm{mg} \cdot \mathrm{L}^{-1}$ um acréscimo de 3,5 \%, já as amostras que atingiram melhores resultados de remoção foram as amostras: 02, 06 e 07 todas com índices de remoção acima dos 60 \%.

Alguns autores utilizaram sementes de $M$. oleífera no tratamento de vinhaça in natura e obtiveram uma redução de 28 \% na DQO sob uma concentração de $250 \mathrm{ml}$ de coagulante por litro de vinhaça. Em alguns estudos com efluentes sanitários apontou que com a utilização de $7000 \mathrm{mg} \cdot \mathrm{L}^{-1}$ de sementes de $M$. oleífera aliado a 500 mg. $\mathrm{L}^{-1}$ de um composto a base de pó de quiabo foi possível reduzir em 84,5 \% a DBO5 do efluente.

As amostras 02 e 06 foram as que produziram os melhores resultados, sendo que na amostra 02 foi utilizado uma concentração de $1 \mathrm{~g} \cdot \mathrm{L}^{-1}$ de pó de Moringa com óleo, já a amostra 06 foi utilizado 0,5 g. $\mathrm{L}^{-1}$ de Moringa sem óleo.

Logo, a amostra 06 foi a que apresentou melhor condição de operação, dado que se utilizou uma menor concentração de $M$. oleífera 0,5 g. $\mathrm{L}^{-1}$ e o óleo já havia sido extraído anteriormente. Desta maneira, torna-se viável após a extração do óleo para produção de biodiesel a utilização das sementes de $M$. oleífera (sem óleo) no tratamento de efluente de vinhaça.

Para Rangel (1999) o óleo extraído das sementes de M. oleífera pode ser utilizado na fabricação de cosméticos, preparo de alimentos, alimentação animal e preparo de biodiesel. Almeida (2012) aponta que através do método Soxhlet é possível extrair $42 \%$ de óleo das sementes de $M$. oleífera, desta forma o autor afirma que o óleo extraído das sementes possui características propícias para produção de biodiesel.

\section{Melhor Concentração Do Pó De Sementes De Moringa Oleifera}

A Tabela 13 apresenta a uma comparação da remoção de COT, DBO 5 e Turbidez entre as 10 amostras distribuídas nas diferentes concentrações do pó das sementes de M. oleífera com e sem óleo comparada com a amostra de efluente após a etapa de eletro floculação.

Tabela 12: Melhor concentração do pó se sementes de Moringa oleifera.

\begin{tabular}{|l|l|l|l|l|}
\hline Amostra & $\begin{array}{l}\text { Concentração de } \boldsymbol{M} . \\
\text { oleifera }\end{array}$ & $\begin{array}{l}\text { Redução ou Acréscimo COT } \\
\text { (\%) }\end{array}$ & $\begin{array}{l}\text { Redução ou Acréscimo } \\
\text { DBO } 5 \text { (\%) }\end{array}$ & $\begin{array}{l}\text { Redução ou Acréscimo } \\
\text { Turbidez (\%) }\end{array}$ \\
\hline Am.01 & $0^{\text {(A) }}$ & $+58,5 \%$ & $+2,5 \%$ & $-72,5 \%$ \\
\hline Am.02 & $1^{(A)}$ & $+84 \%$ & $-71,5 \%$ & $-28 \%$ \\
\hline$A m .03$ & $2^{(A)}$ & $+165,5 \%$ & $-42 \%$ & $+226 \%$ \\
\hline$A m .04$ & $4^{(A)}$ & $+224 \%$ & $-41,5 \%$ & $+299 \%$ \\
\hline$A m .05$ & $8^{(A)}$ & $+293 \%$ & $-1 \%$ & $+1061 \%$ \\
\hline$A m .06$ & $0^{(B)}$ & $+116 \%$ & $-70 \%$ & $-81 \%$ \\
\hline$A m .07$ & $1^{(B)}$ & $+140 \%$ & $-66,7 \%$ & $+50 \%$ \\
\hline Am.08 & $2^{(B)}$ & $-41 \%$ & $+381 \%$ \\
\hline Am.09 & $4^{(B)}$ & $+224 \%$ & $-3,4 \%$ & $+1380 \%$ \\
\hline Am.10 & $8^{(B)}$ & $+305 \%$ & $-8 \%$ & $+1500 \%$ \\
\hline
\end{tabular}

(A) Sementes de M. oleífera com óleo. (B) Sementes de M. oleífera sem óleo.

Na Tabela 13 é possível traçar a eficiência conjunta das amostras com base nos parâmetros COT, $\mathrm{DBO}_{5}$ e turbidez. Nota-se que a amostra 06 apresentou a melhor eficiência, mesmo com um acréscimo nos valores de COT de $116 \%$, houve uma redução significativa na $\mathrm{DBO}_{5}$ e Turbidez $70 \%$ e 81 \% respectivamente. 


\section{Eficiência geral do tratamento}

Foram estabelecidas as melhores condições de operação do sistema de tratamento da efluente vinhaça sendo elas: Etapa de eletrofloculação: Tempo 90 Min. e Intensidade de corrente elétrica 1 A; Etapa do biopolímero de semente de $M$. oleífera: 0,5 g.L $\mathrm{L}^{-1}$ de semente sem óleo.

Desta forma a Tabela 14 apresenta eficiência geral do sistema de eletrofloculação combinado com a utilização do biopolímero natural obtido através do pó das sementes de M. oleífera.

Tabela 13: Eficiência geral do sistema de eletrofloculação combinado com a utilização do biopolímero natural obtido através do pó das sementes de Moringa oleifera.

\begin{tabular}{|l|l|l|l|}
\hline Efluente de vinhaça & COT (mg. L $^{-1}$ ) & DBO $_{\mathbf{5}}$ (mg. $^{-\mathbf{1}}$ ) & Turbidez (UNT) \\
\hline Vinhaça in natura & 248,78 & 6.428 & 35,6 \\
\hline Sistema de tratamento (E.F+ M.O)* & 153,66 & 1.245 & 0,48 \\
\hline Redução & $38,23 \%$ & $80,6 \%$ & $98,5 \%$ \\
\hline
\end{tabular}

* (E.F+ M.O) =Melhor condição etapa eletrofloculação + melhor condição biopolímero M. oleífera.

A Tabela 14 apresenta uma comparação entre a redução de COT, $\mathrm{DBO}_{5}$ e turbidez obtidos neste trabalho comparados aos relatados na literatura por: Paz-Pino et al. (2014), Yavuz (2007), Cardona et al. (2013), Davila et al. (2011) e Santiago et al. (2009) no tratamento de vinhaça.

Tabela 14: Comparação da redução do $\mathrm{COT}, \mathrm{DBO}_{5}$ e turbidez com relatos da literatura

\begin{tabular}{|l|l|l|l|l|l|l|}
\hline Análises & $\begin{array}{l}\text { Paz-Pino et al. } \\
(\mathbf{2 0 1 4})\end{array}$ & $\begin{array}{l}\text { Yavuz } \\
(\mathbf{2 0 0 7})\end{array}$ & $\begin{array}{l}\text { Cardona et al. } \\
(\mathbf{2 0 1 3})\end{array}$ & $\begin{array}{l}\text { Davila et al. } \\
\mathbf{( 2 0 1 1 )}\end{array}$ & $\begin{array}{l}\text { Santiago et } \\
\text { al. (2009) }\end{array}$ & $\begin{array}{l}\text { Presente } \\
\text { trabalho }\end{array}$ \\
\hline $\mathrm{DBO}_{5}$ & $93 \%$ & ---- & ---- & --- & --- & $80,6 \%$ \\
\hline COT & ---- & $88,7 \%$ & $88 \%$ & $25 \%$ & ---- & $38,23 \%$ \\
\hline Turbidez & $99 \%$ & ---- & ---- & $89 \%$ & $90 \%$ & $98 \%$ \\
\hline $\begin{array}{l}\text { Método } \\
\text { utilizado }\end{array}$ & EDF. & EF. & EDF. & $\begin{array}{l}\text { EF. } \\
\text { EC. }\end{array}$ & M.O. & EF. \\
MO. & EC. & FQ. & & \\
\hline
\end{tabular}

(EDF). Eletrodissolução de ferro, (EF) Eletrofloculação, (EC) Eletrocoagulação, (FQ) Floculação Química (MO) M. oleífera, (DA) Digestão Anaeróbica.

Os resultados obtidos em relação à redução do $\mathrm{COT}, \mathrm{DBO}_{5}$ e turbidez do presente trabalho são semelhantes com os relatados na literatura. Com exceção do COT que devido ao a adição do biopolímero de M. oleífera aumentou a concentração de matéria orgânica no efluente, desta forma seria interessante submeter o efluente após a adição do biopolímero uma nova etapa de eletrofloculação a fim de reduzir a concentração de COT.

\section{CONCLUSÕES}

A partir dos ensaios realizados e dos resultados obtidos no presente trabalho, pode-se concluir que: Quanto ao processo de eletrofloculação: Na etapa de eletrofloculação do efluente de vinhaça foi escolhido como condição padrão de operação o tempo de 90 minutos e a intensidade de corrente elétrica em $1 \mathrm{~A}$, uma vez que esses valores apresentaram melhor eficiência na redução dos parâmetros: carbono orgânico total COT, demanda bioquímica de oxigênio $\mathrm{DBO}_{5}$ e turbidez respectivamente $72 \%, 35 \%$, $92 \%$, respectivamente.

Quanto ao processo do biopolímero M. oleífera: A utilização do pó das sementes de M. oleífera com e sem óleo no tratamento de vinhaça apresentaram resultados significativos na redução dos parâmetros: demanda bioquímica de oxigênio $\mathrm{DBO}_{5}$ e turbidez, sob as concentrações de 1 g.L.1 com óleo e $0,5 \mathrm{~g} \cdot \mathrm{L}^{-1} \mathrm{sem}$ 
óleo.

Contudo foi estabelecido como concentração ideal o emprego de $0,5 \mathrm{~g} \cdot \mathrm{L}^{-1}$ do pó da semente de $M$. oleifera sem óleo, uma vez que o óleo das sementes pode ser utilizado na produção de uma série de produtos, dentre eles a produção de biodiesel. Sendo assim a utilização das sementes após o processo de extração do óleo torna-se uma alternativa viável na utilização de $M$. oleífera no tratamento de efluentes de vinhaça.

A utilização do pó das sementes de $M$. oleifera na concentração de $0,5 \mathrm{~g} \cdot \mathrm{L}^{-1}$ sem óleo apresentou-se eficiente na redução de $\mathrm{DBO}_{5}$ e Turbidez apresentando uma redução de $70 \%$ e 81 \%, respectivamente. 0 parâmetro COT não apresentou redução, pelo contrário todas as amostras apresentaram um aumento na concentração de COT durante a etapa de adição do biopolímero de M. oleifera. Este aumento está ligado à adição do pó das sementes de $M$. oleífera, que consequentemente aumenta a concentração de matéria orgânica no efluente.

Quanto a eficiência geral do processo (eletrofloculação e biopolímero de M. oleífera): Analisando a eficiência geral do processo de tratamento de efluentes de vinhaça através da técnica de eletrofloculação aliada com a utilização dos biopolímeros naturais obtidos através do pó das sementes de $M$. oleífera tem-se uma redução global de $38 \%$ do COT, $80 \%$ da $\mathrm{DBO}_{5}$ e $98,5 \%$ da turbidez.

Sendo assim a técnica de eletrofloculação aliada aos biopolímeros das sementes de M. oleífera no tratamento de vinhaça mostrou-se eficiente e viável frente às tecnologias e processos utilizados atualmente no tratamento de efluentes de vinhaça.

\section{REFERÊNCIAS}

ALMEIDA, F. N. C.. Estudo do processo de extração do óleo da semente de Moringa oleífera lam. Visando a produção de biodiesel. Dissertação (Mestrado) - Universidade Estadual de Maringá, Maringá, 2012.

BRASIL, J. L.; VAGHETTI, J. C. P.; ROYER, B.; SANTOS JUNIOR, A. A.; SIMON, N. M.; PAVAN, F. A.; DIAS, S. L. P.; LIMA, E. C.. Planejamento estatístico de experimentos como uma ferramenta para otimização das condições de biossorção de $\mathrm{Cu}$ (II) em batelada utilizando-se casca de nozes pecã como biossorvente. Quim. Nova, v.30, n.3, p.548-53, 2007. DOI: https://doi.org/10.1590/S0100-40422007000300008

BUTTON, S. T.. Metodologia Para Planejamento Experimental E Análise De Resultados. Dissertação (PósGraduação em Engenharia Mecânica) - Universidade Estadual de Campinas, Campinas, 2016.

CARDONA, C.; MACHUCA-MARTINEZ, F.; MARRIAGACABRALES, N.. Treatment of vinasse by using electrodissolution and chemical flocculation. Cali, v.15, n.2, p.191200, 2013.

CARVALHO, T. V.. Biomateriais à base de quitosana de camarão e bactérias para remoção de metais traço e petróleo. Dissertação (Mestrado em Ciências Marinhas Tropicais) - Universidade Federal do Ceará, Fortaleza, 2006.

CERQUEIRA, A. A.; ANDRADE, T. A. G.; MARQUES, M. R. C.; RUSSO, C.. Gestão das águas de produção: histórico, políticas ambientais e alternativa. Tecnológica. Revista Uniara, v.12, n.2, 2009.

CRESPILHO, F. N.; REZENDE, M. O. O.. Eletroflotação: Princípios e Aplicações. São Carlos: RIMA, 2004.

DAVILA, J.; MACHUCA, F.; MARRIAGA, N.. Treatment of vinasses by electrocoagulation- electroflotation using the Taguchi method. Electrochimica Acta, v.56, n.22, p.74337436, 2011. DOI: https://doi.org/10.1016/j.electacta.2011.07.015

EMBRAPA. Empresa Brasileira de Pesquisa Agropecuária. Cana-de-açúcar Adubação: resíduos alternativos. EMBRAPA, 2015.

GALLÃO, M. I.; DAMASCENO, L. F.; BRITO, E. S.. Avaliação química e estrutural da semente de Moringa. Revista Ciência Agronômica, v.37, p.106-109, 2006.

HENNIG, E. L.. Utilização de quitosana obtida de resíduos de camarão para avaliar a capacidade de adsorção de íons Fe3+. Rio Grande, 2009.

HORN, M. M.. Obtenção e caracterização de hidrogéis de quitosana, xantana e colágeno aniônico. São Carlos, 2008.

MELETI, M. V.; FADEL, B.; SMITH, M.. Perspectiva sistêmica da sustentabilidade nas organizações sob a ótica da cultura organizacional e sua repercussão no desenvolvimento 
regional. In: CONGRESSO BRASILEIRO DE SISTEMAS, 8. Anais. Poços de Caldas: Revista Gestão \& Conhecimento, 2012.

PAZ-PINO, O. L.; BARBA-HO, L. E.; MARRIAGA-CABRALES, N.. Vinasse treatment by coupling of electro-dissolution, heterocoagulation and anaerobic digestion.

Medellín, v.81, n.187, p.102-107, 2014. DOI:

http://dx.doi.org/10.15446/dyna.v81n187.38922

POZZOBON, L.; KEMPKA, A. P.. Sementes de moringa oleífera na clarificação de efluente de indústria de ingredientes para alimentação animal: comparação com o coagulante convencional e estudo das condições operacionais. Engevista, v.17, n.2, p.196-206, 2015.

RAMJEAWON, T.. Cleaner production in Mauritian canesugar factories. Journal of Cleaner Production, v.8, n.6, p.503-510, 2000. DOI: https://doi.org/10.1016/S09596526(00)00020-2

RANGEL, M. S. A.. Moringa oleífera: uma planta de uso múltiplo. Aracaju: Embrapa Tabuleiros Costeiros, 1999.

SANTOS, L. M.; REIS, E. M.; SILVA, E. M.; SILVA, F. F.; ZONETTI, P. C.. Tratamento de água residuária de curtume com utilização de sementes de Moringa (Moringa oleífera L.). Revista Agro@mbiente, Boa Vista, v.4, n.2, p.96-101, 2010. DOI: http://dx.doi.org/10.18227/19828470ragro.v4i2.292
SANTIAGO, R. M.; GIRARDI, F.; GIMENES, M. L.. Tratamento de vinhaça com os coagulantes naturais: quitosana, tanino e moringa. In: CONGRESSO BRASILEIRO DE ENGENHARIA QUÍMICA EM INICIAÇÃO CIENTÍFICA, 8. Anais. Uberlândia, 2009.

SILVA, M. A. S.; GRIEBELER, N. P.; BORGES, L. C.. Uso de vinhaça e impactos nas propriedades do solo e lençol freático. Rev. Bras. Eng. Agríc. Ambient., v.11, n.1, p.108114, 2006.

STRÖHER, A. P.; COUTOR JUNIOR, O. M.; MENEZES, M. L.; BERGAMASCO, R.; PEREIRA, N. C.. Aplicação de Moringa oleífera lam no tratamento de efluente proveniente da lavagem de jeans Moringa oleifera lam application in the treatment of effluent from the wash jeans. Revista E-xacta, Belo Horizonte, v.5, n.1, p.61-66, 2012.

VAZ, L. G. L.; KLEN, M. R. F.; VEIT, M. T.; BABIERO, T. A.; BERGAMASCO, R.. Avaliação da eficiência de diferentes agentes coagulantes na remoção de cor e turbidez em efluente de galvanoplastia. Eclet. Quím., São Paulo, v.35, n.4, p.45-54, 2010. DOI: https://doi.org/10.1590/S0100-46702010000400006

VON SPERLING, M.. Introdução à qualidade das águas e tratamento de esgotos. 4 ed. Belo Horizonte: UFMG, 2014.

YAVUZ, Y.. EC and EF processes for the treatment of alcohol distillery wastewater. Separation and Purification Technology, v.53, n.1, p.135-140, 2007.

A CBPC - Companhia Brasileira de Produção Científica (CNPJ: 11.221.422/0001-03) detém os direitos materiais desta publicação. Os direitos referem-se à publicação do trabalho em qualquer parte do mundo, incluindo os direitos às renovaç̃ões, expansões e disseminações da contribuiç̃o, bem como outros direitos subsidiários. Todos os trabalhos publicados eletronicamente poderão posteriormente ser publicados em coletâneas impressas sob coordenação da Sustenere Publishing, da Companhia Brasileira de Produção Científica e seus parceiros autorizados. Os (as) autores (as) preservam os direitos autorais, mas não têm permissão para a publicação da contribuição em outro meio, impresso ou digital, em português ou em tradução. 